\title{
SOLID PHASE EPITAXIAL THICKENING OF BORON AND PHOSPHORUS DOPED POLYCRYSTALLINE SILICON THIN FILMS FORMED BY ALUMINIUM INDUCED CRYSTALLIZATION TECHNIQUE ON GLASS SUBSTRATE
}

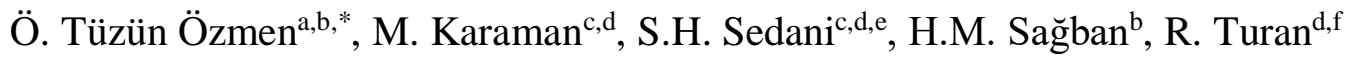 \\ ${ }^{a}$ Department of Fundamental Sciences, İzmir Bakırçay University, 35665 İzmir, Turkey \\ ${ }^{b}$ Department of Physics, Düzce University, 81620 Düzce, Turkey \\ 'Department of Micro and Nanotechnology, Middle East Technical University, 06800 Ankara, Turkey \\ ${ }^{\mathrm{d}}$ GÜNAM, Middle East Technical University, 06800 Ankara, Turkey \\ ${ }^{\mathrm{e}}$ Central Laboratory, Middle East Technical University, 06800 Ankara, Turkey \\ fDepartment of Physics, Middle East Technical University, 06800 Ankara, Turkey
}

\begin{abstract}
:
Aluminium induced crystallization (AIC) technique can be used to form the high-quality and large-grained polycrystalline silicon (poly-Si) thin films, which are with the thickness of $\sim 200 \mathrm{~nm}$ and used as a seed layer, on silicon nitride coated glass substrate. Thanks to aluminium metal in AIC process, the natural doping of AIC thin films is $\mathrm{p}^{+}$type $\left(\sim 2 \times 10^{18} \mathrm{~cm}^{-3}\right)$. On the other hand, recombination of carriers can be controlled by partial doping through the defects that may have advantages to improve the thin film quality by the overdoping induced passivation. In this study, boron (B) and phosphorus (P) doped AIC seed layers were thicken to $\sim 2 \mu \mathrm{m}$ by solid phase epitaxy (SPE) technique at $800^{\circ} \mathrm{C}$ for 3 hours under nitrogen flow in a tube furnace. During the crystallization annealing, exodiffusion of dopants was formed through the SPE film from the AIC seed layer. Optical microscope and electron back scattering diffraction technique (EBSD) were used to analyse the structural quality of the Si films. The poly-Si layer with an average grain size value of $\sim 32 \mu \mathrm{m}$ was formed by AIC+SPE technique for P doped samples while EBSD analysis gave no results for B doped samples due to the quite deterioration on the surface of the films. AIC+SPE films were analysed in terms of structural properties by using micro-Raman Spectroscopy and X-ray diffraction systems. The results showed that the crystallinity of compressive stress formed AIC+SPE films reached up to 98.55\%. Additionally, the Raman analysis pointed out that no temperature-induced stress were generated in the AIC+SPE films while compressive stress was induced by increasing the annealing duration for doped AIC film. For all samples, the preferred orientation was $\langle 100\rangle$, and the crystallite size up to $44.4 \mathrm{~nm}$ was formed by phosphorus doping of AIC films. The doping efficiency was determined by time-of-flight secondary ion mass spectroscopy for doped samples. A graded $\mathrm{n}^{+} \mathrm{n}$ doping profile was obtained by exo-diffusion of phosphorus from the overdoped seed layer during the epitaxial thickening while boron doping of SPE film has failed with exo-diffusion of boron from AIC seed layer into SPE film. Finally, high-quality $\mathrm{n}^{+} \mathrm{n}$ type poly-Si films were fabricated on glass substrate by using AIC+SPE technique.
\end{abstract}

Keywords: Polycrystalline silicon; Thin film; Aluminium induced crystallization; Solid phase epitaxy; Doping process; Glass substrate

*Corresponding Author: Tel: +90 23249300 00; Fax: +90 2328447122

E-Mail: ozge.ozmen@bakircay.edu.tr (Ö. Tüzün Özmen) 


\section{INTRODUCTION}

Photovoltaic solar cells are the most effective energy sources among the traditional energy production methods. Most of the solar cells have the structure of single crystalline silicon (c-Si), amorphous silicon (a-Si), cadmium telluride, copper indium selenide, copper indium gallium selenide and II-VI or III-V semiconductor materials [1]. The c-Si solar cell has high efficiency [2]; however, c-Si wafer production is not cost effective. The price of a large-scale systems is forecasted to drop to $680 \mathrm{US} \$ / \mathrm{KWp}$ in the next 10 years by considering international technology road map for photovoltaics (ITRPV) [3]. The main subject of cost reduction is the material saving in the solar cell production process, especially the silicon, which corresponds to $40 \%$ of the cell price [4]. The crystalline silicon in photovoltaic (PV) production is dominated by $150-200 \mu \mathrm{m}$ wafers; and wafer production below $100 \mu \mathrm{m}$ is highly challenging with the current industry equipments. However, reducing the wafer thickness decreases the PV costs [5]. Therefore, high-quality silicon thin film approach, which allows large-scale applications for cost reduction, is an alternative way of producing solar cells. In this manner, polycrystalline silicon (poly-Si) thin films that having grain sizes of 0.1 and $100 \mu \mathrm{m}$ are the most advantageous structures [6,7]. Poly-Si thin films have 10 to 100 times higher mobility than a-Si thin films [8]. Poly-Si films deposited on a substrate combines the advantages of high efficiency, being cost effective and the stability of c-Si $[9,10,11]$. In addition to this, poly-Si films have the grain boundaries which are the electrical obstacles for the charge carriers and reasonable conversion efficiency values can be obtained by increasing the grain size [12]. Besides, the grain size must be larger than the film thickness in order to reduce the grain boundary recombination effect [13]. Since, the optimum thickness of poly-Si thin film is around $1-4 \mu \mathrm{m}$, an acceptable grain size of poly-Si thin film has to be $\geq 2 \mu \mathrm{m}$ $[14,15]$ 
The most known crystallization techniques that can be used to produce poly-Si thin films [8,9] are: zone melting crystallization, laser induced crystallization, solid phase crystallization (SPC) and metal induced crystallization (MIC). Among these methods, SPC

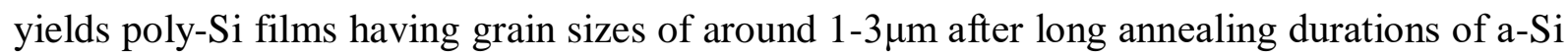
between $24 \mathrm{~h}$ and $48 \mathrm{~h}[16,17]$. On the other hand, high temperature and long annealing durations of SPC technique can be reduced by introducing metals like gold ( $\mathrm{Au})$, aluminium (Al) and nickel (Ni). This technique is named as MIC and generates grain sizes around 15$25 \mu \mathrm{m}$ [18]. Among these metals, $\mathrm{Al}$ does not lead to a contamination in the material and it forms the optimal energy level for the charge carriers compared to other metals [18]. The crystallization of a-Si by using $\mathrm{Al}$ is called the aluminium induced ctystallization (AIC) $[9,18]$.

Since AIC poly-Si is a thin layer $(\sim 200 \mathrm{~nm})$ and a highly doped $\left(\sim 2 \times 10^{18} \mathrm{~cm}^{-3}\right.$ for $\mathrm{p}$ type film), a thick absorber layer $(\sim 2 \mu \mathrm{m})$ is necessary in order to use poly-Si thin films for solar cell applications. Therefore, AIC thin film is used as a seed layer during the epitaxial growth of poly-Si absorber layer [19].

Low-temperature $\left(\leq 800^{\circ} \mathrm{C}\right)$ solid phase epitaxy (SPE) of a-Si by using AIC poly-Si seed layer deposited on glass substrate is a promising approach to obtain poly-Si thin films with high quality [20]. The most significant advantage of this technique is; the AIC poly-Si seed layer has large grain sizes and SPE technique is processed on this seed layer, the final grain sizes of the films are larger than the grain size of the films produced by SPC method [21]. This epitaxial method (AIC+SPE) combines the advantages of AIC and SPC techniques [21]. SPE method allows low-temperature applications $\left(\leq 800^{\circ} \mathrm{C}\right)$ on substrates like glass. Therefore, solar cells having large grain size and high quality that can be produced by using AIC+SPE technique. As a result, electrically and optically improved structures can be obtained. 
Poly-Si film quality and solar cell production cost are directly related to substrate choice [22]. Wide variety of substrates like glass [23,24], ceramics [25,26], glass-ceramics [27,28], stainless steel $[29,30]$, graphite $[31,32]$ have been used for poly-Si thin film production. To avoid stress and cracks in the thin film, the thermal expansion coefficients of substrate and silicon $\left(4.2 \times 10^{-6} \mathrm{~K}^{-1}\right)$ must match with each other. Furthermore, the substrate has to be refractory during the film growth and cost effective for the solar cell production. Considering these criteria, borosilicate glass, having thermal expansion coefficient of $3 \times 10^{-6} \mathrm{~K}^{-1}$ and heat resistant up to $650-750^{\circ} \mathrm{C}$ with $20-30 € / \mathrm{m}^{2}$ cost, can be nominated as a suitable preference [23].

N-type and p-type silicon materials have different electrical properties. As given in Ref. [33], a dramatic decline in resistivity can be seen for n-type and p-type polycrystalline silicon when low doped and medium doped levels are compared. This situation proceeds until the c-Si values are reached at high doping levels. However, it is obvious that n-type material indicates a lower resistivity than p-type material between $10^{17}$ and $10^{20} \mathrm{~cm}^{-3}$ doping range.

In Ref. [18], it is definitely stated that, n-type material has better carrier lifetime and diffusion length compared to p-type silicon. Especially, the difference between the diffusion lengths is quite large at low carrier density values $\left(10^{17}-10^{18} \mathrm{~cm}^{-3}\right)$. Additionally, in Ref. [34], the electrical properties of n-type multicrystalline silicon are better than p-type multicrystalline silicon. In the light of these results, n-type material seems to be more advantageous than p-type material for thin film solar cell fabrication. Therefore, compared to p-type silicon films, n-type films have the advantages of having better defect tolerance, higher diffusion length make n-type films more reliable than p-type films $[18,35]$. On the other hand, recombination of carriers can be controlled by partial doping through the defects. Moreover, p-type silicon solar cells have a restricted efficiency. The performance of p-type solar cells is degraded as exposed to light. This tendency can be attributed to the formation of boron- 
oxygen complex that is quite active in terms of recombination [36]. Considering these advantages, potentially n-type solar cells enable high efficiency values.

In this study, p-type and n-type AIC+SPE poly-Si films were fabricated on boron (B) and phosphorus (P) doped AIC seed layers, respectively. The aim of producing boron-doped $\mathrm{p}^{+}$-type film instead of $\mathrm{Al}$-doped $\mathrm{p}^{+}$-type film is that the boron has quite similar parameters with phosphorus, such as diffusion coefficient, silicon binding energies and energy levels in silicon. At the same time, this is not the case for aluminum doping, while boron can be doped in a controlled manner. Thus, it is expected that the p-type material (boron doped) and the ntype material (phosphorus doped) can be compared in the most reliable and accurate way. In this study, the SPE technique was carried out for the boron and phosphorus doped AIC film on glass substrate.

\section{EXPERIMENTAL}

In this study, new types of glass substrates (SCHOTT AF32 ECO) that can withstand temperatures up to $850^{\circ} \mathrm{C}$ and have a thickness of $1.1 \mathrm{~mm}$ were used as substrate. In order to prevent diffusion of impurities (B, Al, etc.) from the glass into the Si thin film during thermal annealing at high temperatures and to increase the adhesion of silicon and glass with different thermal expansion coefficients, glass surface is coated with a silicon nitride $\left(\mathrm{SiN}_{\mathrm{x}}\right)$ interlayer that has the thickness of $\sim 80 \mathrm{~nm}$ and was deposited by plasma enhanced chemical vapour deposition (PECVD) system which was deposited by decomposition of ammonia $\left(\mathrm{NH}_{3}\right)$ and silane $\left(\mathrm{SiH}_{4}\right)$ precursor gases. During the $\mathrm{SiN}_{\mathrm{x}}$ deposition the gas pressure inside the chamber was kept at $1.3 \times 10^{2} \mathrm{~Pa}$, and the substrate temperature $\left(\mathrm{T}_{\mathrm{s}}\right)$ was $200^{\circ} \mathrm{C} . \mathrm{NH}_{3}$ and $\mathrm{SiH}_{4}$ gases with $\mathrm{NH}_{3} / \mathrm{SiH}_{4}=2$ ratio and $100 \mathrm{~W}$ system power were used to deposit $\mathrm{SiN}_{\mathrm{x}}$.

The formation of $\mathrm{SiN}_{\mathrm{x}}$ buffer layer was followed by $\mathrm{Al}$ deposition $(\sim 180 \mathrm{~nm})$ by using thermal evaporation method. During Al evaporation, the deposition rate was about $3 \mathrm{~nm} / \mathrm{s}$, and 
pressure was kept between $8 \times 10^{-4}$ and $1 \times 10^{-3} \mathrm{~Pa}$. Prior to a-Si deposition the samples were exposed to ambient air in clean room conditions for 1 week to form native aluminium oxide $\left(\mathrm{AlO}_{\mathrm{x}}\right)$ that provides a controllable layer exchange of $\mathrm{Al}$ and $\mathrm{Si}$. After the formation of $\mathrm{AlO}_{\mathrm{x}}$ layer, about $360 \mathrm{~nm}$ of a-Si was deposited by electron beam (e-beam) evaporation system. The deposition of a-Si was performed by evaporation of ultra pure (99.9999 \%) silicon chunks. The processes were accomplished by $8.5 \mathrm{kV}$ fixed e-beam voltage and $60-70 \mathrm{~mA}$ current emission. During the process the pressure was kept between $8 \times 10^{-7}$ and $1.3 \times 10^{-4} \mathrm{~Pa}$ while the deposition rate and substrate temperature were $10 \AA / \mathrm{s}$ and $200^{\circ} \mathrm{C}$, respectively. Ebeam system allows a good homogeneity of the layers thanks to rotating holder. The deposition systems have in-situ thickness measurement facility by quartz thickness monitor. Then, the samples were annealed in a classical tube furnace at $500^{\circ} \mathrm{C}$ for 5 hours under nitrogen $\left(\mathrm{N}_{2}\right)$ flow to crystallize the a-Si by the layers exchange process, which forms the continuous poly-Si thin films. Finally, the "glass/SiN ${ }_{\mathrm{x}} /$ poly-Si/(Al+Si)" structure was obtained after thermal annealing. In order to prepare the surface of Si film for the further processes, the residual Al layer was removed by selective wet chemical etching using a $\mathrm{H}_{3} \mathrm{PO}_{4} / \mathrm{H}_{2} \mathrm{O} / \mathrm{CH}_{3} \mathrm{COOH} / \mathrm{HNO}_{3}$ solution at $40^{\circ} \mathrm{C}$ with a $16: 2: 1: 1$ ratio, while $\mathrm{Si}$ islands were etched by nonselective $\mathrm{HNO}_{3} / \mathrm{HF} / \mathrm{H}_{2} \mathrm{O}$ solution with a ratio of 72.5:1.5:28. The resulting AIC poly-Si film is $\mathrm{p}^{+}$-type due to $\mathrm{Al}$ doping during $\mathrm{AIC}$ process.

After the production of AIC poly-Si seed layer, boron and phosphorus doping of AIC poly-Si films were carried out by spin coating method. The polycrystalline silicon films formed by AIC method are intrinsically $\mathrm{p}^{+}$-type silicon materials, thanks to Al dopant. Indeed, $\mathrm{p}^{+}$-type AIC poly-Si film is formed directly due to the presence of $\mathrm{Al}$ in poly-Si layer and serves as a back surface field with a carrier concentration of $\sim 2 \times 10^{18} \mathrm{~cm}^{-3}$.

On the other hand, in order to observe the effects of phosphorus and boron doping on the produced AIC layers, AIC poly-Si films were converted into boron doped $\mathrm{p}^{+}$- type and 
phosphorus doped $\mathrm{n}^{+}$-type films using B202 and P509 liquid solutions containing boron and phosphorus, respectively, provided by Filmtronics Ltd. The P509 solution contains $10.5 \%$ phosphorus dopant while the B202 solution contains $5 \%$ boron dopant. 50 $\mu \mathrm{L}$ of P509 or B202 solutions were dropped onto the AIC poly-Si film by means of a micropipette and coated homogeneously on the surface with a spin coating system at $3000 \mathrm{rpm}$. Immediately after spin coating, samples were held in oven at $200^{\circ} \mathrm{C}$ for approximately 15 minutes to evaporate the solvents in the doping solutions. Subsequently, for thermal diffusion of the doping solutions through the AIC poly-Si film, the samples were exposed to thermal annealing in a tube furnace under $\mathrm{N}_{2}$ flow. Annealing was carried out at $850^{\circ} \mathrm{C}$ for 1 hour to dope the AIC film by phosphorus dopant while boron doping was carried out at $850^{\circ} \mathrm{C}$ for $1,2,3$ and 5 hours. After thermal diffusion, the samples were dipped in a 10:1 mixture of deionized water (DI$\mathrm{H}_{2} \mathrm{O}$ ) : hydrofluoric acid (HF) for 1 minute to remove the residual phosphorus, and then thoroughly rinsed for 5 minutes in DI- $\mathrm{H}_{2} \mathrm{O}$. Thus, with this surface cleaning process, samples were prepared for the SPE process on AIC poly-Si films. In order to fabricate poly-Si film by SPE method, a-Si of $\sim 2 \mu \mathrm{m}$ thickness was deposited on AIC layers by electron beam evaporation system with a deposition rate of $12 \AA / s$. For the crystallization of the a-Si films, the samples were annealled at $800^{\circ} \mathrm{C}$ for 3 hours under $\mathrm{N}_{2}$ flow in a tube furnace. Both p-type and n-type films have been produced as the absorber layer since both the boron-doped $\mathrm{p}^{+}$-type and the phosphorus-doped $\mathrm{n}^{+}$-type films are fabricated as the AIC seed layer.

The surface images of AIC+SPE films were studied by optical microscope and the grain images of the samples were analyzed by electron back scattering diffraction (EBSD) system. Raman and X-ray diffraction (XRD) measurements were performed to analyse the crystallinity and the crystal structure of AIC+SPE films. The electrical properties of the AIC+SPE layer were investigated using four point probe conductivity measurement system. 


\section{RESULTS AND DISCUSSIONS}

\subsection{Boron and phosphorus doping of AIC seed layer}

The success of the phosphorus and boron doping processes of AIC poly-Si films with a thickness of approximately $200 \mathrm{~nm}$ was investigated by the sheet resistances $\left(\mathrm{R}_{\square}\right)$ obtained from the results of the four-point probe conductivity measurements. Table 1 shows the sheet resistances of undoped and doped AIC poly-Si films.

As shown in Table 1 , the sheet resistance values are reduced from $5.75 \mathrm{k} \Omega / \mathrm{sq}$ for the undoped AIC layer down to $0.085 \mathrm{k} \Omega / \mathrm{sq}$ after phosphorus diffusion at $850^{\circ} \mathrm{C}$ for 1 hour by using P509 phosphorus solution. This result shows that phosphorus doping is successful at $850^{\circ} \mathrm{C}$ for 1 hour and AIC poly-Si films converted from $\mathrm{p}^{+}$type to $\mathrm{n}^{+}$type. The same inclination is true for poly-Si filmin boron doping. However, as a result of 1, 2 and 3 hours annealing processes, the sheet resistance has still been in $\mathrm{k} \Omega$ order. These results show that boron doping of the AIC layer is not as efficient as phosphorus doping as a result of 1, 2 and 3 hours annealing at $850^{\circ} \mathrm{C}$. The enhancement in annealing time for the boron doping results the decline in the sheet resistance, which leads to a further increase in annealing time. Therefore, annealing of boron doping has been increased from 3 hours to 5 hours. As a result of this, the sheet resistance value was found to be $0.11 \mathrm{k} \Omega / \mathrm{sq}$. According to this result, boron doping of AIC poly-Si film was successful at $850^{\circ} \mathrm{C}$ for 5 hours.

It is very important to examine the effects of heat treatment applied to the contribution of dopant atoms and dopant diffusion on film quality (such as stress, crystallinity) in $\mathrm{p}^{+}$and $\mathrm{n}^{+}$ AIC poly-Si films produced by boron and phosphorous doping. Because the goal is not only the successful completion of the doping process but also the fact that the doping does not have any negative effect on the quality of the produced films.

Due to the presence of $\mathrm{Al}$ during the production phase, using an extra doping technique for AIC layer, which is naturally $\mathrm{p}^{+}$type, can cause alterations in the film structure 
since these atoms can either bond with silicon atoms or remain unbound. The bond structure of film can change and the interactions between the atoms may vary since the boron and phosphorus atoms are different from the volume of the bulk Si atoms. These changes may impose a stress on the material. Raman analysis of boron and phosphorus doped AIC films was performed to investigate these possible effects. Raman analysis gives the information on the amount of stress calculated from the peak position as well as the crystallization amounts of boron and phosphorus doped films under different conditions.

Figure 1a gives the Raman analysis of phosphorus-doped AIC poly-Si films. Here, the temperatures are different from the $850^{\circ} \mathrm{C} / 1$ hour used for the above-mentioned phosphorus doping. The reason for this is lowering the temperature to $800^{\circ} \mathrm{C}$ with this work and reducing the amount of film stress that would be caused by the effect of temperature in the film. On the other hand, the duration of diffusion at $800^{\circ} \mathrm{C}$ was extended to 3,6 and 18 hours due to the reduction in diffusion temperature. This is also the case for boron doping. Therefore, Raman analysis was carried out for boron doped AIC samples in order to investigate the effects of 5 and 20 hours diffusion annealing at $800^{\circ} \mathrm{C}$, and the analysis results are shown in Figure $1 \mathrm{~b}$.

There appears to be an expansion in the Raman peaks for the boron- and phosphorusdoped AIC poly-Si films when these are compared with the Raman peaks of c-Si. Therefore, the full width at half maximum (FWHM) value, which is an important parameter and indicates the crystallization quality in poly-Si films, was analysed for the phosphorus and boron-doped AIC poly-Si films given both in Figures 1a and 1b. FWHM values of boron and phosphorus doped AIC poly-Si films are given in Table 2.

Considering the FWHM values given in Table 2, the FWHM values of films produced with additional doping range from $5.12 \mathrm{~cm}^{-1}$ to $5.54 \mathrm{~cm}^{-1}$. The FWHM value of the AIC polySi film without additional doping is $4.85 \mathrm{~cm}^{-1}$, while the FWHM values of boron and phosphorus doped samples are up to $5.54 \mathrm{~cm}^{-1}$. The values listed in Table 2 are higher than the 
FWHM value for c-Si, i.e. $4.09 \mathrm{~cm}^{-1}$, but this excess is not very large. It is known that the smaller the FWHM value, the better the material and the better the crystal structure are. It is then expected that the FWHM value for poly-Si films is higher than the FWHM value for cSi. Since the structure of AIC poly-Si films includes defects and grains, this causes a difference in the quality of the crystal compared to c-Si. On the other hand, when the FWHM values given in Table 2 were compared with those of the AIC poly-Si films without additional doping, the increase in the FWHM values of the doped films were observed. In the boron and phosphorus-doped samples, there was a slight increase in FWHM values compared to undoped AIC films since the doping atoms $(\mathrm{B}, \mathrm{P})$ are located in non-active regions in the material and, particularly, the deposits into the grain boundaries make the material even more defective. On the other hand, as seen in Table 2, the FWHM values for both phosphorus and boron doped AIC poly-Si films are also increasing by the enhancement in annealing duration. The reason behind the increase of the amount of defects in the film is that as the annealing duration for AIC poly-Si films increases, more doping atoms diffuse into the film.

In this context, when the FWHM values of AIC poly-Si films are taken into consideration, an increase is observed in FWHM values by increasing the duration of doping for both boron and phosphorus. The type and amount of stress formed in the films as a result of AIC film doping can be analysed in detail by Raman analysis. As shown in Figures 1a and $1 \mathrm{~b}$, for boron and phosphorus doped AIC films, a right shift to the larger wave numbers is observed for the Raman peaks of all annealed samples compared to the Raman peak position of the $\mathrm{c}-\mathrm{Si}\left(521 \mathrm{~cm}^{-1}\right)$. This behaviour is quite compatible with the literature [37].

The shift towards larger wave lengths indicates that compressive stress is present for all AIC samples [38]. Raman peak positions of phosphorus-doped films were $521.68 \mathrm{~cm}^{-1}$ and $522.36 \mathrm{~cm}^{-1}$ for 3 and 6 hours annealing, respectively, while it reached $522.81 \mathrm{~cm}^{-1}$ at the end of the 18 hours annealing. Raman peak positions of boron-doped films also increased from 
$522.8 \mathrm{~cm}^{-1}$ to $523.7 \mathrm{~cm}^{-1}$ after 5 and 20 hours annealing, respectively. In this case, as the annealing time for the doping increases, the positions of the Raman peaks shift further to the right, i.e. the compressive stress increases. The amount of compressive stress generated in these films can be calculated by the following equation $[18,39]$ :

$$
\sigma(M P a)=-250\left(\omega_{s}-\omega_{0}\right)
$$

where $\omega_{s}$ is the wavenumber of the stressed poly-Si and $\omega_{0}$ is the wavenumber of the stress free single crystalline Si $\left(521 \mathrm{~cm}^{-1}\right)$. By using Eq. (1), the compressive stress amounts of $170 \mathrm{MPa}$ and 340MPa are calculated for n-type AIC film produced by 3 hours annealing and 6 hours annealing, respectively, whereas the compressive stress value is increased to $452.5 \mathrm{MPa}$ for 18 hours annealing. Hereby, the significant increase in the doping annealing time, i.e. the increase in the exposure of the sample to heat, entails a significant increase in the amount of compressive stress that occurs in the AIC poly-Si film structure. Compressive stress values of the boron doped samples are $450 \mathrm{MPa}$ for 5 hours annealing and it is increased to $675 \mathrm{MPa}$ when the annealing time is increased to 20 hours. According to this result, as in phosphorus doping case, the amount of compressive stress in poly-Si films increases with increasing in the annealing time of boron doping, too.

By considering all the aforementioned results, we can see that the 3 hours annealing for phosphorus and the 5 hours annealing for boron are the optimum values. It would be wrong to arrive at this result clearly, unless the formation of the SPE layer and the diffusion phenomenon in the SPE layer are examined in details during experiments. ,. 
3.2. Fabrication of poly-Si absorber layer by SPE technique on $p^{+}$and $n^{+}$types of AIC poly-

\section{Si films produced at different doping concentrations}

In this study, crystallization experiments for the SPE technique were carried out at $800^{\circ} \mathrm{C}$ for 3 hours, while not exceeding the glass durability limits $\left(\leq 850^{\circ} \mathrm{C}\right)$ and considering diffusion of phosphorus and boron. At the same time, the exo-diffusion of the doping atoms from the AIC seed layer into the SPE layer was aimed with the crystallization of SPE film by thermal annealing. In this part, firstly, the optimization of AIC+SPE poly-Si film's annealing temperature was studied; then, the effects of crystallization and doping diffusion on AIC and SPE interface were investigated. The formed interface is directly correlation with the binding of dopants to AIC film surface, i.e. the diffusion temperature of the dopant materials. Therefore, the differences in SPE films were analyzed according to the different doping temperatures of AIC poly-Si films by keeping the AIC+SPE film's annealing condition constant at $800^{\circ} \mathrm{C}$ for 3 hours. Annealing times were selected at extreme values to clearly observe the effects of phosphorus and boron doping of the AIC poly-Si seed layer on the SPE film. The AIC layer was annealed at $850^{\circ} \mathrm{C}$ for 3 hours ( $3 \mathrm{hP}$ sample), 6 hours ( $6 \mathrm{hP}$ sample) and 18 hours (18hP sample) for phosphorus doping. In order to produce boron doped AIC film, the AIC film was annealed at $850^{\circ} \mathrm{C}$ for 5 hours (5hB sample) and 20 hours (20hB sample). Figure 2 shows the results of Raman spectroscopy of $\sim 2 \mu \mathrm{m}$ thick n-type and p-type SPE films (AIC+SPE) formed on AIC seed layer and crystallized at $800^{\circ} \mathrm{C}$ for 3 hours. In addition to doped samples, c-Si and undoped sample comparisons are given as reference. In Figure 2, the peak positions of phosphorus doped $(3 \mathrm{hP}, 6 \mathrm{hP}, 18 \mathrm{hP})$ and boron doped $(5 \mathrm{hB}$, 20hB) SPE samples appear at the same wavelenght with the Raman peak positions of undoped reference and $\mathrm{c}-\mathrm{Si}$. This shows that no stress is produced in all films although they are subjected to different AIC doping processes. As discussed above, the right (compressive) or left (tensile) shift of the peak positions according to the Raman peak position of the c-Si 
that indicates the formation of stress in the film. As a conclusion, no temperature-induced stress is generated in the AIC+SPE films since none of the AIC+SPE samples shown in Table 2 have shift when compared with the Raman peak of c-Si.

Raman analysis can also provide information about the amount of crystallization as mentioned above. Since the SPE layer is fabricated on the AIC seed layer, it is expected to yield a high crystallization rate. Crystallinity (crystalline fraction- $X_{c}$ ) of the poly-Si absorber layers formed by the SPE technique on phosphorus-doped $\left(\mathrm{n}^{+}\right.$-type $)$and boron-doped $\left(\mathrm{p}^{+}-\right.$ type) AIC poly-Si films were calculated using the Peak Fit program.

In our calculations, intensity of peaks obtained from Raman analysis for all samples were used. In addition, the FWHM values that give information about the crystal quality of AIC+SPE films are showen in Table 2.

As indicated in Table 2, very high amounts (95.85-98.55\%) of crystallization were obtained for boron and phosphorus doped AIC+SPE poly-Si films. This indicates that SPE annealing for 3 hours at $800^{\circ} \mathrm{C}$ is quite sufficient. On the other hand, for the doped samples there is a decrease in the amount of crystallization as compared to the reference sample (undoped). The reason of this behaviour can be the formation defects, even if they are in small quantities. These defects that may have a inhibitory effect on the crystallization of the film result from the presence of the diffused doping atoms at the grain boundaries or in nonbonded states. The increase in FWHM values of the doped poly-Si films specified in Table 2 also supports this interpretation. When the FWHM values of the AIC layer given in Table 2 and the FWHM values of the AIC+SPE layers given in Table 2 are compared, the FWHM values of the AIC films are slightly lower. This may be due to the huge amount of defects due to contamination that may diffuse into the SPE layer from the interface between the AIC and the SPE layers. Crystallization of AIC+SPE poly-Si films was also studied by XRD measurements in addition to Raman analysis. Moreover, the XRD technique can be used to 
obtain information about different crystal orientations and crystallite sizes. Using XRD measurements, different crystal orientations can be analyzed. The distribution analysis of these orientations can be accomplished by calculating the crystallographic orientation factors $\Theta_{\mathrm{hkl}}$ of the samples, and the preferential orientation for the poly-Si film can be acquired in this way. $\Theta_{\mathrm{hk}}$ were normalized with respect to different diffraction peak intensities obtained on a randomly orientated polycrystalline powder taken as a reference. The preferred crystal orientation $\Theta_{\mathrm{hkl}}$ is determined by the 6 selected spectral lines by using [40,41]: The crystal orientation factors $\Theta_{\mathrm{hkl}}(\%)$ obtained as a result of these calculations are given in Figure 3.

$$
\Theta_{h k l}=100 \times \frac{I_{h k l} / I_{0 k h l}}{\sum_{h k l} I_{h k l} / I_{0 h k l}}
$$

where $I_{h k l}$ and $I_{0 h k l}$ represent the diffracted intensities in the $\theta-2 \theta$ spectra of respectively the poly-Si film and Si reference powder for each $\langle h k l\rangle$ orientation. The XRD peak height for poly-Si is normalized by $[1-\exp (-2 \mu t / \sin \theta)]$. The reason of the normalization is to take the finite film thickness into consideration. In this normalization definition, $\mu, t$ and $\theta$ are the $\mathrm{X}$ ray absorption coefficient $\left(=143.1 \mathrm{~cm}^{-1}\right)$, the film thickness and the X-ray angle of incidence, respectively. The crystal orientation factors $\Theta_{\mathrm{hkl}}(\%)$ are given in Figure 3.

By considering the orientation factors shown in Figure 3, it is seen that in all samples with both boron doping and phosphorus doping, preferential orientation is $\langle 100\rangle$ independent of production conditions. Approximately $42-44 \%$ of the total surface is $\langle 100\rangle$ oriented. The orientation factor analysis obtained as a result of XRD analysis for the AIC seed layer also indicates that the AIC poly-Si seed layer has a $<100>$ preferential orientation. In this case, it is expected that the preferred orientation of the AIC+SPE structure is $\langle 100\rangle$, which is an indication that the SPE layer has taken the AIC layer as a guide. 
The XRD peaks can be used to calculate the crystallite size, which is the coherent diffraction domain in the film, of the poly-Si films by using the Scherrer equation $[42,43]$.

$$
D=\frac{0.9 \lambda}{\beta \cos \theta}
$$

where $D$ represents the crystallite size, $\lambda$ is wavelength $(1.54059 \AA), \beta$ is the FWHM of peaks and $\theta$ represents the diffraction angle. According to the XRD results that are not shown here, the crystallite sizes for phosphorus and boron doped AIC+SPE poly-Si samples were calculated for $\langle 100\rangle$ peak and listed in Table 2 since the most significant peak for all samples is $\langle 100\rangle$.

As shown in Table 2, the crystallite sizes of boron- and phosphorus-doped AIC+SPE poly-Si films range from $32.3 \mathrm{~nm}$ to $44.4 \mathrm{~nm}$. Thus, a high-quality Si films was produced using AIC+SPE technique. On the other hand, it is seen that the crystallite sizes decrease in the doped samples by increasing the annealing duration. The reason of this may be due to the increase in the amount of doping atoms and defects caused by increasing the annealing time, which may result in the decrease in the crystallite size. This complies with the discussion in the annealing time and the crystal quality described in Table 2 for the doped AIC poly-Si films.

Detailed analysis of the crystallization of AIC+SPE samples has been examined by Raman and XRD measurements and it has been observed that boron and phosphorus doping have nota serious effect on crystallization of the films. However, the most efficient way to analyze the effects of boron and phosphorus doping on poly-Si films is to make elaborate analysis on the surfaces of AIC+SPE samples by optical microscope.

Surface morphologies of undoped reference, boron- and phosphorus-doped AIC+SPE samples are shown in Figure 4. 
When the optical microscope images shown in Figure 4 are considered, the effects of doping the AIC layer and doping materials on the AIC+SPE surfaces are quite clear. While the surface of undoped reference sample is smoother, the doping process causes partly (for phosphorus) or quite (for boron) deterioration on the surface of the films. In the case of doped samples, the surface fluctuates by increasing the doping time. The most basic reason for this is that the doping solutions can not be completely cleaned at the interface between the AIC layer and the SPE layer. This is quite obvious for boron doped samples. The amount of oxygen in the interface significantly affects the SPE layer's surface condition. The surface of boron doped samples is rougher since boron reacts more easily with oxygen than phosphorus.

It is discovered that the boron solution (containing oxygen) at the interfaces of the boron doped AIC samples can not be cleaned with dilute HF after the thermal annealing while a large portion of the phosphorus solution (containing oxygen) at the AIC and SPE interface of the phosphorus-doped AIC samples can be cleaned with dilute HF after annealing of the phosphorus-doped AIC samples. In this case, as a result of the SPE crystallization annealing for the boron-doped samples, the interfaces became active.

In addition to optical microscope, the structural quality of the Si films can also be monitored by electron back scattering diffraction technique (EBSD). In particular, the EBSD technique can serve as a powerful tool to extract more information from the same data such as the texture and the grain sizes. The grain size is obtained by the EBSD technique that is different than the calculation of the crystallite size by the XRD technique,. For this reason, grain sizes are calculated in $\mu \mathrm{m}$ order with EBSD technique while the crystallite sizes are calculated in $\mathrm{nm}$ order by using the XRD technique. In this study, EBSD measurements for phosphorus and boron doped samples are made simultaneously. However, EBSD measurements can not be performed due to the quite deterioration on the surface of the boron doped films that is shown in Figure 4c, EBSD analysis was carried out only for phosphorus- 
doped AIC+SPE films. The crystalline orientation map for SPE poly-Si film formed on phosphorus-doped AIC seed layer is shown in Figure 5. Orientation maps have $70 \times 100 \mu \mathrm{m}^{2}$ for EBSD image, with a mapping step of $0.5 \mu \mathrm{m}$. The colors of orientation mapping show the crystallographic orientation of grains and the standard color triangle that shows a prominent three dimensional texture shown in inset of each orientation map. Additionally, the mean of each color is written at the figure caption. The grain orientation related texture can be examined by the grains whose similar crystal orientations are shown in similar colors.

As discussed above, crystallite size is the smallest - most likely single crystal in powder form and usually measured from X-ray diffraction patterns while grain is either a single crystalline or polycrystalline material, and is present either in bulk or thin film form. Therefore, the grain is larger than a crystallite and formed by several of the crystallites [44]. The grain morphology is commonly determined by EBSD. Orientation maps as shown in Figure 5 are very useful to evaluate the grain size. The grain size can be estimated by summing up over number of data points in each grain. The SPE Si film on phosphorus doped AIC seed layer attains $\sim 32 \mu \mathrm{m}$ average grain size. Furthermore, the continuous AIC+SPE poly-Si film was obtained with the preferred orientation of $\langle 100\rangle$. According to these results, it is revealed that the prefer grains orientation for epi-layer $\langle 100\rangle$, similar to that of underlying AIC seed layer. Additionally, for $2 \mu \mathrm{m}$-thick AIC+SPE films that were fabricated on $200 \mathrm{~nm}$ thick AIC poly-Si film, the average grain size of $\sim 32 \mu \mathrm{m}$ and $<100>$ preferred orientation is also quite compatible with the literatures $[45,46]$. The result of this EBSD orientation also coincided well with the result of the crystal orientation calculated from the XRD measurements.

The time-of-flight secondary ion mass spectrometry (ToF-SIMS) measurements were performed to precisely investigate either the diffusion of phosphorus and boron into the SPE layer from the AIC layer or the effect of the interface on diffusion of the doping atoms. The 
contribution profiles in the films can be clearly comprehended with ToF-SIMS analysis. However, ToF-SIMS only provides information on the amount of atoms. Figure 6 shows the ToF-SIMS analysis of AIC+SPE samples doped with phosphorus (sample of $3 \mathrm{hP}$ ) and boron (sample of $5 \mathrm{hB})$.

By considering the phosphorus profile shown in Figure 6a, phosphorus atoms in the AIC layer actively diffuse into the SPE layer as a result of a 3 hour annealing at $800^{\circ} \mathrm{C}$ for the crystallization of the SPE layer, while the AIC layer has a phosphorus concentration of about $10^{19} \mathrm{~cm}^{-3}$ for the $3 \mathrm{hP}$ sample. As a result of the diffusion process, the concentration of phosphorus in the SPE layer decreased gradually to around $10^{15} \mathrm{~cm}^{-1}$. According to this result, the out-diffusion of phosphorus from the AIC seed layer into the SPE layer was successfully carried out by the SPE crystallization annealing process. As a result, the graded $\mathrm{n}^{+}-\mathrm{n}$ profile that was aimed was achieved by 3 hours crystallization annealing for phosphorus-doped samples. Such graded $n^{+}-n$ structure is highly suited for the polycrystalline thin film silicon solar cells. Indeed, it induces a drift-field effect that as beneficial in the case of materials with low minority carrier's diffusion length as it is the case for poly-Si films [18].

The boron profile deduced from the ToF-SIMS analysis for boron doped AIC+SPE sample is shown in Figure 6b. As shown in Figure 6b, ToF-SIMS analysis of boron doped AIC+SPE poly-Si film gave a very interesting boron profile. It is clear for boron-doped film that the boron can not diffuse into the SPE film from the AIC seed layer even if the boron diffuses into SPE film, the boron concentration would be very low. Since the ToF-SIMS system can not make concentration analyzes of atoms having a concentration below $10^{15} \mathrm{~cm}^{-3}$, the data below $10^{15} \mathrm{~cm}^{-3}$ can not be shown clearly by using ToF-SIMS system.

In that case, boron from the $\sim 200 \mathrm{~nm}$ thick AIC film could only diffuse $\sim 1 \mu \mathrm{m}$ gradually; however, the ToF-SIMS system could not show the boron profile since the boron concentration in the SPE film was lowered to below $10^{15} \mathrm{~cm}^{-3}$ when approaching the 
polysilicon surface. This is quite consistent with optical microscope images. According to the optical microscope images, the SPE process made on the interfaces that can not be cleaned completely for the boron-doped samples and the oxygen in the interface became active by thermal annealing and the bumps were observed on the surface for the boron coated sample as shown in Figure 4. As evidenced by the boron profile, this interface oxide layer prevented boron diffusion from the AIC seed layer into the SPE film, so that the boron atoms could not diffuse fully into the SPE film from the AIC film. Finally, it can be concluded that SPE film can be successfully doped by the exo-diffusion of phosphorus from AIC seed layer into SPE film while boron doping of SPE film has failed with exo-diffusion of boron from AIC seed layer into SPE film. Therefore, for solar cell applications, p-type AIC+SPE film needs to be doped in a different technique.

\section{CONCLUSION}

In this study, p- and n-type poly-Si thin films were fabricated by using AIC+SPE technique which combines all advatages of AIC and SPE techniques by combining large-grained and high-quality material. In this study, the SPE technique was carried out for the boron and phosphorus doped AIC film on glass substrate. Firstly, AIC poly-Si film which is intrinsically $\mathrm{p}^{+}$-type thanks to aluminium dopant with a carrier concentration of $\sim 2 \times 10^{18} \mathrm{~cm}^{-3}$ was doped by boron and phosphorus due to their higher diffusion coefficient that is important for the exodiffusion of dopant from AIC layer into epitaxial layer. Boron and phosphorus atoms may alter the bond structure of film and interaction between the atoms since the volume of boron and phosphorus atoms is different from the volume of $\mathrm{Si}$ atoms. To analyse these effects, we studied the boron and phosphorus doped AIC poly-Si films. The analysis of doped AIC layer by phosphorus doping annealing at $850^{\circ} \mathrm{C}$ for 1 hour and boron doping annealing at $850^{\circ} \mathrm{C}$ for 1, 2 and 3 hours showed that more dopant atoms diffuses into the film for both phosphorus 
and boron doped AIC poly-Si films by increasing the diffusion annealing time for the boron and phosphorous AIC film, which increases the amount of defects in the film. On the other hand, compressive stress was formed in the films since the dopant of AIC films was carried out at high temperatures $\left(\sim 800^{\circ} \mathrm{C}\right)$. Additionally, the FWHM value that indicates the best crystallinity of the samples with the lowest value was obtained for shorter doping annealing durations for both phosphorus and boron doped AIC films. By considering the analysis of exsitu doped AIC poly-Si films, it can be concluded that 3 hours for phosphorus and 5 hours for boron are the optimum values for the doping of AIC films. To thicken the $~ 200 \mathrm{~nm}$ thick AIC poly-Si film for solar cell applications, SPE technique was used on boron and phosphorus doped AIC films. For SPE technique, $\sim 2 \mu \mathrm{m}$ thick a-Si deposited on doped AIC seed layers for different doping durations was crystallized at $800^{\circ} \mathrm{C}$ for 3 hours. The analysis of thin films indicated that stress free and continuous poly-Si films with high crystallization rates $(\geq 97 \%)$ were fabricated by using $\mathrm{AIC}+\mathrm{SPE}$ technique. Additionally, in all $\mathrm{AIC}+\mathrm{SPE}$ samples with both boron doping and phosphorus doping, preferential orientation is $<100\rangle$ independent of production conditions. The crystallite sizes of boron- and phosphorus-doped AIC+SPE polySi films range from $32.3 \mathrm{~nm}$ to $44.4 \mathrm{~nm}$, which is quite promising for AIC+SPE poly-Si films. On the other hand, the doping process causes partly (for phosphorus) or quite (for boron) deterioration on the surface of the films while the surface of undoped reference sample is smoother. Since it is not possible to completely clean the surface of boron-doped AIC seed layer with HF and boron reacts more easily with oxygen, the surface of boron doped samples is rougher than phosphorus doped samples. Finally, it can be concluded that graded $n^{+}-n$ doped poly-Si film with the average grain size of $\sim 32 \mu \mathrm{m}$ was succeffully fabricated by using AIC+SPE technique while boron doping of SPE film has failed with exo-diffusion of boron from AIC seed layer into SPE film due to the oxygen at the interface. 


\section{ACKNOWLEDGEMENT}

This work has been funded by TÜBİTAK under the project number $112 \mathrm{~T} 084$ and the

Scientific Research Project Fund of Düzce University under the project number 2017.05.02.623.

REFERENCES: 
TABLES:

Table 1.

\begin{tabular}{cccccc}
\hline \hline & \multicolumn{5}{c}{$\mathbf{R}_{\square}$ values $(\mathbf{k} \mathbf{\Omega} / \mathbf{s q})$} \\
\cline { 2 - 6 } Sample & $\begin{array}{c}\text { without } \\
\text { annealing }\end{array}$ & $1 h @ 850^{\circ} \mathrm{C}$ & $2 h @ 850^{\circ} \mathrm{C}$ & $3 h @ 850^{\circ} \mathrm{C}$ & $5 h @ 850^{\circ} \mathrm{C}$ \\
\hline $\mathrm{n}^{+}$type AIC & & 0.085 & - & - & - \\
\hline $\mathrm{p}^{+}$type AIC & & 2.27 & 1.91 & 1.2 & 0.11 \\
\hline undoped AIC & 5.75 & & & \\
\hline \hline
\end{tabular}


Table 2.

\begin{tabular}{|c|c|c|c|c|}
\hline \multirow[b]{2}{*}{ Samples } & \multirow{2}{*}{$\begin{array}{c}\text { AIC poly-Si films } \\
F W H M\left(\mathrm{~cm}^{-1}\right)\end{array}$} & \multicolumn{3}{|c|}{ AIC + SPE poly-Si films } \\
\hline & & $F W H M\left(\mathrm{~cm}^{-1}\right)$ & $X_{c}(\%)$ & $\begin{array}{c}\text { Crystallite } \\
\text { Size }(\mathrm{nm})\end{array}$ \\
\hline $\begin{array}{l}\text { Reference } \\
\text { (Undoped) }\end{array}$ & 4.85 & 6.20 & 99.4 & 44.0 \\
\hline $3 \mathrm{hP}$ & 5.25 & 6.52 & 98.55 & 44.4 \\
\hline $6 \mathrm{hP}$ & 5.47 & 6.76 & 98.24 & 38.8 \\
\hline $18 \mathrm{hP}$ & 5.54 & 6.88 & 95.85 & 37.8 \\
\hline $5 \mathrm{hB}$ & 5.12 & 6.93 & 98.43 & 39.4 \\
\hline $20 \mathrm{hB}$ & 5.27 & 7.02 & 97.75 & 32.3 \\
\hline
\end{tabular}




\section{Highligths}

- Silicon film was formed by aluminum induced crystallization and solid phase epitaxy

- Polycrystalline silicon (poly-Si) seed layers were doped by boron and phosphorus

- The structural analysis showed that $\langle 100\rangle$ is the preferred orientation for Si films

- Graded $\mathrm{n}^{+}-\mathrm{n}$ doped poly-Si film with the average grain size of $\sim 32 \mu \mathrm{m}$ was fabricated

[1] J.-C. Muller, P. Siffert, Silicon for Photovoltaics, in: P. Siffert, E. Krimmel (Eds.), Silicon, Evolution and Future of a Technology, Springer, 2004, pp. 73-92.

[2] M.A. Green, Y. Hishikawa, W. Warta, E.D. Dunlop, D.H. Levi, J. Hohl-Ebinger, A.W.H. Ho-Baillie, "Solar cell efficiency tables (version 50)", Progress in Photovoltaics 25 (2017) 668-676. https://doi.org/10.1002/pip.2909.

[3] International Technology Roadmap for Photovoltaic (ITRPV): 2016 Results, Revision 1, 2016. www.itrpv.net (accessed 10 January 2019)

[4] International Renewable Energy Agency, Renewable Energy Technologies: Cost Analysis Series - Solar Photovoltaics, Volume I: Power Sector, IRENA Secretariat, Abu Dhabi; 2012.

[5] D.B. Needleman, J.R. Poindexter, R.C. Kurchin, I.M. Peters, G. Wilson, T. Buonassisi, Economically sustainable scaling of photovoltaics to meet climate targets, Energy Environ. Sci. 9 (2016) 2122-2129. https://doi.org/ 10.1039/c6ee00484a.

[6] D. Van Gestel, I. Gordon, H. Bender, D. Saurel, J. Vanacken, G. Beaucarne, J. Poortmans, Intragrain defects in polycrystalline silicon layers grown by aluminuminduced crystallization and epitaxy for thin-film solar cells, J. Appl. Phys. 105 (2009) 114507. https://doi.org/10.1063/1.3117838.

[7] P.A. Basore, Defining terms for crystalline silicon solar cells, Prog. Photovoltaics Res. Appl. 2 (1994) 177-179. https://doi.org/10.1002/pip.4670020213.

[8] S.W. Lee, Y.C. Jeon, S.K. Joo, Pd induced lateral crystallization of amorphous Si thin films, Appl. Phys. Lett. 66 (1995) 1671-1673. https://doi.org/10.1063/1.113888.

[9] G. Beaucarne, A. Slaoui, "Thin Film Polycrystalline Silicon Solar Cells", In: J. Poortmans, V. Arkhipov (Eds.), Thin Film Solar Cells , John Wiley \& Sons, 2006, pp. $97-$ 131.

[10] R.B. Bergmann, J.H. Werner, The future of crystalline silicon films on foreign substrates, Thin Solid Films 403-404 (2002) 162-169. https://doi.org/10.1016/S0040-6090(01)01556-5.

[11] R. Brendel, Thin-Film Crystalline Silicon Solar Cells: Physics and Technology, WileyVCH Verlag GmbH \& Co. KGaA, Weinheim , 2003.

[12] M. Imaizumi, T. Ito, M. Yamaguchi, K. Kaneko, Effect of grain size and dislocation density on the performance of thin film polycrystalline silicon solar cells, J. Appl. Phys. 81 (1997) 7635-7640. https://doi.org/10.1063/1.365341.

[13] R.B. Bergmann, R. Brendel, M. Wolf, P. Lölgen, J. Krinke, H.P. Strunk, J.H. Werner, Growth of polycrystalline silicon films on glass by high-temperature chemical vapour deposition, Semicond. Sci. Technol. 12 (1997) 224-227. https://doi.org/10.1088/02681242/12/2/012.

[14] M.S. Spitzer, J. Shewchun, E.S. Vera, J.J. Loferski, Ultra high efficiency thin silicon p-n junction solar cells using reflecting surfaces, Proceedings of the 14th IEEE Photovoltaic Specialists Conference, 375-380 (January 1980). 
[15] K. Ishii, H. Nishikawa, T. Takahashi, Y. Hayashi, Sub-5 $\mu \mathrm{m}$ thin film crystalline silicon solar cell on alumina ceramic substrate, Jpn. J. Appl. Phys. 32 (1993) L770-L773. https://doi.org/10.1143/JJAP.32.L770.

[16] D. Song, A. Straub, P.Widenborg, B. Vogl, P. Campbell, Y. Huang, A.G. Aberle, Polycrystalline silicon thin-film solar cells on glass by solid phase crystallization of in-situ doped evaporated a-Si, Proceedings of the 19th European Photovoltaic Solar Energy Conference, 1193-1196 (June 2004).

[17] Z. Yu, X. Geng, Y. Sun, S. Liu, H. Li, J. Lu, J. Sun, Z. Sun, W. Xu, Super large grain size of poly-Si obtained by using the solid-phase crystallization method, Phys. Status Solidi A 144 (1994) 393-399. https://doi.org/10.1002/pssa.2211440219.

[18] Ö. Tüzün, "Polycrystalline Silicon Films by Aluminium Induced Crystallization and Epitaxy: Synthesis, Characterizations and Solar Cells", Ph.D. Thesis, Université de Strasbourg, 2009. http://scd-theses.u-strasbg.fr/1681/01/TUZUN_Ozge_2009r.pdf (accessed 17 January 2019)

[19] I. Gordon, D. Van Gestel, K. Van Nieuwenhuysen, L. Carnel, G. Beaucarne, J. Poortmans, Thin-film polycrystalline silicon solar cells on ceramic substrates by aluminiuminduced crystallization, Thin Solid Films $487 \quad$ (2005) 113-117. https://doi.org/10.1016/j.tsf.2005.01.047.

[20] A.V. Zotov, V.V. Korobtsov, Present status of solid phase epitaxy of vacuum-deposited silicon, J. Cryst. Growth 98 (1989) 519-530. https://doi.org/10.1016/0022-0248(89)90170-X.

[21] Per I. Widenborg, A. Straub, A.G. Aberle, Epitaxial thickening of AIC poly-Si seed layers on glass by solid phase epitaxy, J. Cryst. Growth 276 (2005) 19-28. https://doi.org/10.1016/j.jcrysgro.2004.10.155.

[22] S. Reber, T. Kieliba, S. Bau, Crystalline Silicon Thin Film Solar Cells on Foreign Substrates by High Temperature Deposition and Recrystallization, In: J. Poortmans, V. Arkhipov (Eds.), Thin Film Solar Cells, John Wiley \& Sons, 2006, pp. 39-95.

[23] R. Bergmann, J. Kühnle, J.H. Werner, S. Oelting, M. Albrecht, H.P. Strunk, K. Herz, M. Powalla, Polycrystalline silicon for thin film solar cells, Proceedings of the 1994 IEEE First World Conference on Photovoltaic Energy Conversion, 1398-1401 (December 1994).

[24] G. Andra, J. Bergmann, E. Ose, M. Schmidt, N.D. Sinh, F. Falk, Multicrystalline LLCsilicon thin film cells on glass, Proceedings of the 29th IEEE Photovoltaic Specialists Conference 1306-1309 (May 2002).

[25] S. Minagawa, T. Saitoh, T. Warabisako, N. Nakamura, H. Itoh, T. Tokuyama, Fabrication and characterization of solar cells using dendritic silicon thin films grown on alumina ceramic, Proceedings of the 12th IEEE Photovoltaic Specialists Conference 77-81 (November 1976).

[26] J.A.M. van Roosmalen, C.J.J. Tool, R.C. Huiberts, R.J.G. Beenen, J.P.P. Huijsmans, W.C. Sinke, Ceramic substrates for thin-film crystalline silicon solar cells, Proceedings of the 25th IEEE Photovoltaic Specialists Conference 657-660 (May 1996).

[27] A. Slaoui, M. Rusu, A. Focsa, R. Torrecillas, E. Alvarez, A. Gutjar, Investigation of barrier layers on ceramics for silicon thin film solar cells, Proceedings of the 29th IEEE Photovoltaic Specialists Conference 90-93 (April 2002).

[28 ] I. Gordon, K. Van Nieuwenhuysen, L. Carnel, D. Van Gestel, G. Beaucarne, J. Poortmans, Toward Efficient Thin-Film Polycrystalline-Silicon Modules using Interdigitated Top Contacts, Proceedings of the 2006 IEEE 4th World Conference on Photovoltaic Energy Conversion 2066- 2069 (May 2006).

[29] A.M. Barnett, M.G. Mauk, R.B. Hall, D.A. Fardig, J.B. McNeely, Design and development of efficient thin-film crystalline silicon solar cells on steel substrates, Proceedings of the 6th European Photovoltaic Solar Energy Conference866-870 (April 1985). 
[30] A.M. Barnett, R.B. Hall, D.A. Fardig, J.S. Culik, Silicon-film solar cells on steel substrates, Proceedings of the 18th IEEE Photovoltaics Specialists Conference 1094-1099 (October 1985).

[31] T. Kunze, S. Hauttmann, J. Seekamp, J. Müller, Recrystallized and epitaxially thickened poly-silicon layers on graphite substrates, Proceedings of the 26th IEEE Photovoltaic Specialists Conference 735-738 (September 1997).

[32] R. Monna, D. Angermeier, A. Slaoui, J.C. Muller, G. Beaucarne, J. Poortmans, C. Hebling, Poly-Si thin films on graphite substrates by rapid thermal chemical vapor deposition for photovoltaic application, Proceedings of the 14th European Photovoltaic Solar Energy Conference 1456-1459 (June 1997).

[33] H.J. Moller, Semiconductors for Solar Cells, Artech House Publishers, Norwood, MA, 1993.

[ 34 ] S. Martinuzzi, O. Palais, S. Ostapenko, Scanning techniques applied to the characterisation of $\mathrm{P}$ and $\mathrm{N}$ type multicrystalline silicon, Mater. Sci. Semicond. Process. 9 (2006) 230-235. https://doi.org/10.1016/j.mssp.2006.01.079.

[35] D. Macdonald, L.J. Geerligs, Recombination activity of interstitial iron and other transition metal point defects in p- and n-type crystalline silicon, Appl. Phys. Lett. 85 (2004) 4061-4063. https://doi.org/10.1063/1.1812833.

[36] J. Schmidt, A. Cuevas, Electronic properties of light-induced recombination centers in boron-doped Czochralski silicon, J. Appl. Phys. $86 \quad$ (1999) 3175-3180. https://doi.org/10.1063/1.371186.

[ 37 ] N.H. Nickel, P. Lengsfeld, I. Sieber, Raman spectroscopy of heavily doped polycrystalline silicon thin films, Phys. Rev. B 61 (2000) 15558-15561. https://doi.org/10.1103/PhysRevB.61.15558.

[38] S. Boultadakis, S. Logothetidis, S. Ves, Comparative study of thin poly-Si films grown by ion implantation and annealing with spectroscopic ellipsometry, Raman spectroscopy, and electron microscopy, J. Appl. Phys. 72 (1992) 3648-3658. https://doi.org/10.1063/1.352308.

[39] V. Paillard, P. Puech, M.A. Laguna, P. Temple-Boyer, B. Caussat, J.P. Couderc, B. de Mauduit, Resonant Raman scattering in polycrystalline silicon thin films, Appl. Phys. Lett. 73 (1998) 1718-1720. https://doi.org/10.1063/1.122256.

[40] P. Joubert, B. Loisel, Y. Chouan, L. Haji, The effect of low pressure on the structure of LPCVD polycrystalline silicon films, J. Electrochem. Soc. 134 (1987) 2541-2545. https://doi.org/10.1149/1.2100239.

[41] S. Bourdais, R. Monna, D. Angermeier, A. Slaoui, N. Rauf, A. Laugier, F. Mazel, Y. Jorand, G. Fantozzi, Combination of RT-CVD and LPE for thin siliconfilm formation on alumina substrates, Proceedings of the 2nd World Conference on Photovoltaic Solar Energy Conversion 1774-1777 (July 1998).

[42] H.P. Klug, L.E. Alexander, X-Ray Diffraction Procedures: For Polycrystalline and Amorphous Materials, 2nd Ed., John Wiley \& Sons, New York, 1974.

[43] M.E. Rabanal, A. Várez, B. Levenfeld, J.M. Torralba, Magnetic properties of Mg-ferrite after milling process, J. Mater. Process. Technol. 143-144 (2003) 470-474. https://doi.org/10.1016/S0924-0136(03)00464-3.

[44] J.R. Ares, A. Pascual, I.J. Ferrer, C. Sánchez, Grain and crystallite size in polycrystalline pyrite thin films, Thin Solid Films 480-481 (2005) 477-481. https://doi.org/10.1016/j.tsf.2004.11.064.

[45] R. Numata, K. Toko, N. Saitoh, N. Yoshizawa, N. Usami, T. Suemasu, Orientation Control of Large-Grained Si Films on Insulators by Thickness-Modulated Al-Induced Crystallization, Cryst. Growth Des. 13 (2013) 1767-1770. https://doi.org/10.1021/cg4000878. 
[46] K. Toko, R. Numata, N. Saitoh, N. Yoshizawa, N. Usami, T. Suemasu, 2014. Selective formation of large-grained, (100)- or (111)-oriented $\mathrm{Si}$ on glass by Al-induced layer exchange. J. Appl. Phys. 115, 094301. https://doi.org/10.1063/1.4867218. 


\section{LIST OF TABLE CAPTIONS:}

Table 1. The sheet resistances $\left(R_{\square}\right)$ values measured by the four-point probe conductivity system for the undoped and doped AIC poly-Si films.

Table 2. The FWHM and crystalline fraction $\left(X_{c}\right)$ values deduced from the Raman analysis for the phosphorus and boron doped AIC and AIC+SPE poly-Si films. Additionally, the crystallite sizes of SPE poly-Si films according to $<100>$ orientation on undoped, boron- and phosphorus-doped AIC seed layers were also given. 


\section{LIST OF FIGURE CAPTIONS:}

Figure 1. Raman analysis of (a) phosphorus- and (b) boron-doped AIC poly-Si films as a function of doping annealing. Raman analysis of undoped AIC (i.e. boron and phosphorus not doped AIC) film and c-Si are given as reference.

Figure 2. Raman analysis of SPE layers produced on (a) phosphorus- and (b) boron-doped AIC poly-Si films.

Figure 3. Crystallographic orientation factors obtained from XRD peaks for (a) phosphorusdoped and (b) boron-doped AIC+SPE films.

Figure 4. Optical microscope images of (a) undoped, (b) phosphorus- and (c) boron-doped AIC+SPE poly-Si films.

Figure 5. Orientation mapping analysis of phosphorus-boron-doped AIC+SPE poly-Si films. The colors indicate: red $=\langle 100\rangle \pm 15^{\circ}$, blue $=\langle 111\rangle \pm 15^{\circ}$, green $=\langle 101\rangle \pm 15^{\circ}$.

Figure 6. ToF-SIMS analysis of AIC+SPE samples: (a) phosphorus profile of the phosphorus doped sample and (b) boron profile of the boron doped sample. 